\title{
QUALITY CHANGES DURING SUMMER - AUTUMN LONG TERM STORAGE OF BIRCH (BETULA PENDULA) ROUNDWOOD
}

\author{
Jānis Magaznieks, Mareks Millers, Zelma Gžibovska \\ Latvia University of Agriculture \\ janis.magaznieks@inbox.lv
}

\begin{abstract}
The homogeneous and light wood of birch is suitable for different types of treatment processes and is highly valued for products where visual aspect is important, however, birch assortments are highly susceptible to damages caused by fungi during the storage. Such fungal damages cause discoloration of birch roundwood intended for further woodworking.

Sapwood discoloration development and its influencing factors for birch roundwood were analyzed in the summer autumn period of the year 2016 (August, September and October). Control cut for assessment of sapwood discoloration development was made in four birch roundwood stacks in the districts of Auce and Daugavpils. In order to evaluate the influence of harvesting type, side surface damages, placement in pile, storage duration, diameter, distance from the end plane, daily average temperatures, precipitation amount and relative humidity on development of sapwood discoloration, 616 discs from birch log end planes were prepared.

After conducting multiple factor linear regression, it was concluded that a significant development of discoloration and its changes for birch roundwood are promoted by harvesting type, placement in pile, distance from the end plane, daily average temperatures and relative humidity $\left(\mathrm{R}^{2}=0.450\right)$. For birch logs that are prepared by harvester with the daily average air temperature $+6{ }^{\circ} \mathrm{C}$, the first signs of discoloration appear after 17 - 18 days, but on all logs stacked in pile they appear after $68-69$ days. Whereas, with the daily average temperature of $+18{ }^{\circ} \mathrm{C}$, the first signs of discoloration can occur after only six days, but on all logs stacked in pile they appear after 23 days.
\end{abstract}

Key words: birch round assortments, storage, discoloration.

\section{Introduction}

Roundwood after logging is stored in the forest near the road from where it is later transported to the processing sites. Timber storage duration in such cases is uncertain both in the forest near the road and in the stowage area, so sometimes these materials remain vulnerable to various types of damage. Logs that are stored unprotected against different types of damage for a long time, remain susceptible to biological staining (Uzunovic et al., 2008).

During the summer, when storing birch logs, the main problem is sapwood fungal lesions that stain wood in brown colour, thus reducing the round timber quality. After logging, the sapwood colouring rises from the end surface inwards. The mechanical properties of both the conifer and birch wood are not affected, but the quality and economic value of lumber products significantly decrease. Colour changes may occur by oxidation when the air penetrates into the wood and reacts with the wood substance. One explanation is that the living parenchyma cells begin to produce substances that can react with oxygen (Corbo et al., 2001; Stahl et al., 2005).

Fungi and bacteria may also be involved in the sapwood staining processes. They have a major role in the staining processes of tree species sapwood (Shigo, 1965; Hallaksela \& Niemisto, 1998). Mechanisms of sapwood coloring during the storage begin to work from the end plane and are not fully understood (Corbo et al., 2001; Stahl et al., 2005).

When storing birch and other tree species, staining of this kind occurs only in combination with slow drying of logs outdoors. In a similar way, during the storage other species - beech (Fagus sylvatica), maple (Acer platanoides), ash (Fraxinus excelsior), aspen (Populus tremula) - got stained (Nylinder et al., 2007).

Birch end surface sapwood discolouration may progress rapidly - by several hundred millimeters in just 2 weeks (Nylinder et al., 2001). Sapwood colour changes can be difficult to distinguish from the false heartwood, which is widespread birch defect appearing in the growth process.

The study that was made in Sweden (Jonsson, 2013) reveals birch and aspen sapwood discoloration trends, when storing logs in two different ways: standard - under natural conditions after felling, and when using irrigation. During the storage, the colouring increased for logs prepared in both winter and spring. Significantly more staining developed on birch logs compared to alder and aspen. There were no differences between logs prepared in winter and spring. Logs, which were sprinkled, showed less discoloration changes compared to the standard method of storage, especially after 12 weeks of storage.

The aim of this research was to determine the quality changes of birch (Betula Pendula) during summer-autumn long-term storage. When working with large volumes of roundwood, it requires constant wood forwarding and transport to the sawmills. This was the main reason for creating this study and getting an understanding on how to optimize the entire cycle from harvesting till the primary processing of the timber. In the future, this study may help to understand 
the economic loss that a seller gets for every day that timber is stored for too long, thus failing to ensure the seller with maximum revenue from the log sales. Similarly, the results of the study can be used in practice by forest managers, harvester operators and timber logistics planners, who, knowing the factors that influence roundwood quality changes and their thresholds, can plan the technological process of logging and timber transport more accurately, avoiding (or minimizing) the quality reduction of roundwood.

\section{Materials and Methods}

Factors affecting birch round timber discoloration development were analysed in the study's third stage of the 2016 summer-autumn period (August, September and October). Control cuttings for determination of sapwood discoloration development were carried out in the open storages of birch round assortments in the Auce and Daugavpils regions.

In order to evaluate the preparation type, side surface damage type, placement in the storage, storage length, diameter, distance from the end plane, the daily average temperature, precipitation amount and relative humidity effects on discoloration development, 616 sample discs were prepared from the ends of birch round assortments.

Sample storage consists of $26-32$ (on average 30 ) round assortments with $10-30 \mathrm{~cm}$ diameter and 1 meter length (see Fig.1). As it is known that sapwood discoloration and crooks are mainly developing from the end plane, 1 meter long assortments are enough to evaluate the quality changes from the round timber end planes.

The evaluation of round timber placement in the storages:

- $1-9$ assortments are characterizing the quality changes at the bottom of the storage (round timber placement on the ground);

- $11-16$ and $19-23$ assortments are characterizing the quality changes in the middle of the storage;
- $10,17,18$ and $24-30$ assortments are characterizing the quality changes on the top of the storage.

In order to assess the variety of preparation ways, four timber storages were created simultaneously in each plot with different damages of side surface.

- Control - assortments without side surface damages.

- Damaged bark - assortments with the side surface of the bark bruised over the entire length.

- Harvester spike roller damages - assortments that have damages from harvester pike roller, but do not have bruised bark made by debarking knives.

- Harvester spike roller and bark damages assortments with bruised bark and damaged side surface by harvester spike roller.

The inspection of birch round assortments was carried out at least once a week, but control cuttings started after 3 weeks of storage. In every control cutting, around 8-9 round assortments for determination of discoloration proportion were examined - 2-3 from the ground assortments, 2-3 from the middle and top assortments.

Discs of the assortment were sawn off in one survey, as shown in the scheme (Fig. 2). For the first disc on the outside, only sapwood was sawn 3-5 mm in depth, in order to assess the quality requirements of assortments at purchasing. Every subsequent disc was sawn in $50 \mathrm{~mm}$.

After preparation of sample discs, it is necessary to mark the wood discoloration border. Further the numbering for taking photos was applied - the number shows the distance in $\mathrm{cm}$ from the end plane. To describe the proportion of discoloration, it is necessary to determine the percentage of wood discoloration. Therefore, sapwood and discoloration basal area of sample discs were calculated by using special image processing software 'ImageJ'. A lower average air temperature results in longer storage

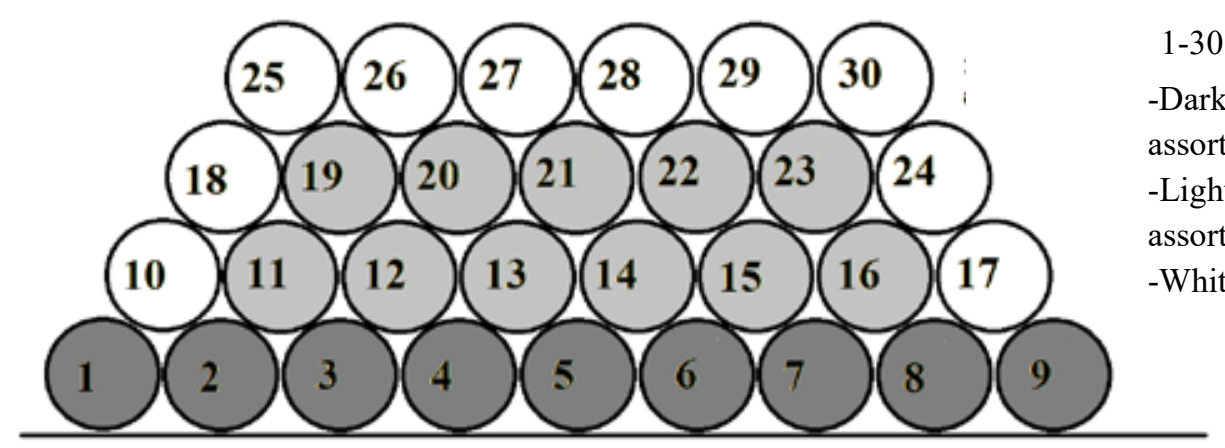

1-30 - number of the $\log$

-Dark grey - ground assortments

-Light grey - middle assortments

-White - top assortments

Figure 1. The scheme of assortment emplacement. 
$3-5 \mathrm{~mm} 50 \mathrm{~mm} \mathrm{100mm} \mathrm{150mm} \mathrm{200mm}$

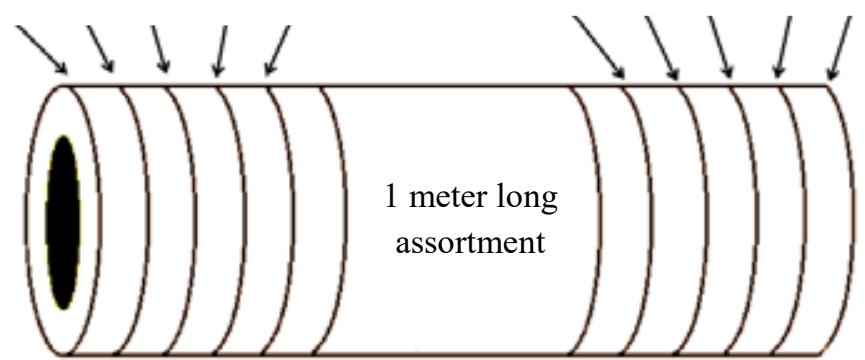

$200 \mathrm{~mm} 150 \mathrm{~mm} 100 \mathrm{~mm} 50 \mathrm{~mm} 3-5 \mathrm{~mm}$

Figure 2. Roundwood cross-cuting section length. periods, whereas a higher average air temperature results in shorter storage periods. In order to get the meteorological data, temperature and precipitation were obtained from www.meteo.lv by using the data of the nearest meteorological station. The sum of positive temperature during storage period was used.

In order to achieve weather discoloration area statistically significantly differ between birch round assortments depending on influencing factors two independent sample mean values are presented with \pm 2 standard errors which are characterized by a $95 \%$ confidence interval. If two independent samples with $95 \%$ confidence intervals overlap with each other, then the difference between them will not be statistically significant.

\section{Results and Discussion}

In the start of the drying process, after the tree felling and cross-cutting, the moisture content of wood decreases in accordance with the current climate, wood properties and bark damages. Decreasing moisture content of wood results in an increased risk of discoloration. When the relative moisture of wood decreases below $50 \%$, the risk of wood staining increases noticeably (Peek \& Liese, 1974; Liese \& Peek, 1984).

At the beginning, when surveying the birch round timber storages, the attention was paid to the point at which (the depth of $5 \mathrm{~mm}$ from the end plane) the first signs of sapwood discoloration would appear. For browning development, nutrients, oxygen, appropriate temperature and humidity are needed. In optimal conditions, discoloration can occur after just a few days. Therefore, in this analysis as a key influencing factor of discoloration development is the air temperature - the sum of daily average air temperatures during the storage period.

The development of the sapwood discoloration is shown in Table 1, depending on the average daily temperature and different side surface damages. In this case, by obtained results, all assortments can be divided into two birch round assortment groups:

- Control assortments and assortments with a damaged bark - prepared with the chainsaw;

- Assortments with the harvester spike roller damages and assortments with the harvester

\section{Intervals of sapwood discoloration depending on the daily average temperature}

\begin{tabular}{|c|c|c|c|c|}
\hline \multirow{3}{*}{$\begin{array}{l}\text { Daily average } \\
\text { temperature, }{ }^{\circ} \mathrm{C}\end{array}$} & $\begin{array}{l}\text { First signs of } \\
\text { discoloration }\end{array}$ & $\begin{array}{l}\text { Discoloration on all } \\
\text { assortments }\end{array}$ & $\begin{array}{l}\text { First signs of } \\
\text { discoloration }\end{array}$ & $\begin{array}{c}\text { Discoloration on all } \\
\text { assortments }\end{array}$ \\
\hline & \multicolumn{4}{|c|}{ Storage time, days } \\
\hline & \multicolumn{2}{|c|}{ Control } & \multicolumn{2}{|c|}{ Harvester spike roller damages } \\
\hline 6 & 24 & 71 & 18 & 68 \\
\hline 10 & 14 & 43 & 11 & 41 \\
\hline 14 & 10 & 30 & 8 & 29 \\
\hline \multirow[t]{2}{*}{18} & 8 & 24 & 6 & 23 \\
\hline & \multicolumn{2}{|c|}{ Damaged bark } & \multicolumn{2}{|c|}{ Harvester spike roller and bark damages } \\
\hline 6 & 23 & 69 & 17 & 69 \\
\hline 10 & 14 & 42 & 10 & 41 \\
\hline 14 & 10 & 30 & 7 & 30 \\
\hline 18 & 8 & 23 & 6 & 23 \\
\hline
\end{tabular}


spike roller and bark damages - prepared by the harvester.

The most attention was paid to two daily average temperatures +6 and $+18{ }^{\circ} \mathrm{C}$. At 5 to $+6{ }^{\circ} \mathrm{C}$, sapwood discoloration had started, but at 18 to $+20{ }^{\circ} \mathrm{C}$ optimal conditions for sapwood discoloration fungi development were provided. When the birch round assortments are prepared with a chainsaw at the average daily temperature $\left(+6^{\circ} \mathrm{C}\right)$, the first signs of sapwood discoloration appear after 23 to 24 days of storage, but on all assortments sapwood discoloration appears after 69 to 71 days. If the average daily temperature reaches $+18{ }^{\circ} \mathrm{C}$, the first signs of sapwood discoloration appear after 8 days, but on all assortments, sapwood discoloration appears after 23 to 24 days.

When the birch round assortments are prepared with the harvester at average daily temperature $+6{ }^{\circ} \mathrm{C}$, the first signs of sapwood discoloration appear after 17 to 18 days of storage, but on all assortments sapwood discoloration appears after 68 to 69 days. If the average daily temperature reaches $+18{ }^{\circ} \mathrm{C}$, the first signs of sapwood discoloration appear after 6 days, but on all assortments sapwood discoloration appears after 23 days.

Based on these results, it can be concluded that for birch round assortments, which are prepared with harvester at similar conditions, discoloration develops faster, compared to assortments prepared with a chainsaw.

Considering the above mentioned influencing factors, in further analysis it will be described how the placement in the storage influences staining process.
It has been proven before that the placement in the storage and the preparation type also influence the water evaporation intensity; it also depends on wind and direct sunshine intensity.

For birch round wood assortments, which are prepared by the chainsaw and are stored for 3 weeks on the top portion of the storage, the proportion discoloration is around 48\% from cross-sectional sapwood area. In further storage period, the same birch round assortments have no significant increase in the proportion of discoloration (47 to $50 \%$ ). For the birch round wood assortments that are stored for 3 weeks in the middle section of the storage, the discoloration proportion takes up to $30 \%$ of the cross-sectional sapwood area. After 6 weeks the discoloration proportion more than doubles (77\%) and after 9 weeks it is $84 \%$. The most intensive development of sapwood discoloration for birch occurs for the assortments stored in the bottom section of the storage. Birch logs that are in direct contact with soil show 39\% after 3 weeks and up to $98 \%$ of sapwood discoloration proportion after 6 weeks of storage.

For birch round wood assortments, which are prepared by harvester, discoloration tendencies are similar to assortments, which are prepared with the chainsaw. After 3 weeks of storage on the top portion of the storage, the proportion discoloration is around $55 \%$ from the cross-sectional sapwood area. After 6 weeks, for the same birch round assortments the proportion of discoloration is around $61 \%$, but after 9 weeks around $78 \%$. For the birch round wood assortments that are stored for 3 weeks in the middle section of the storage, the discoloration proportion

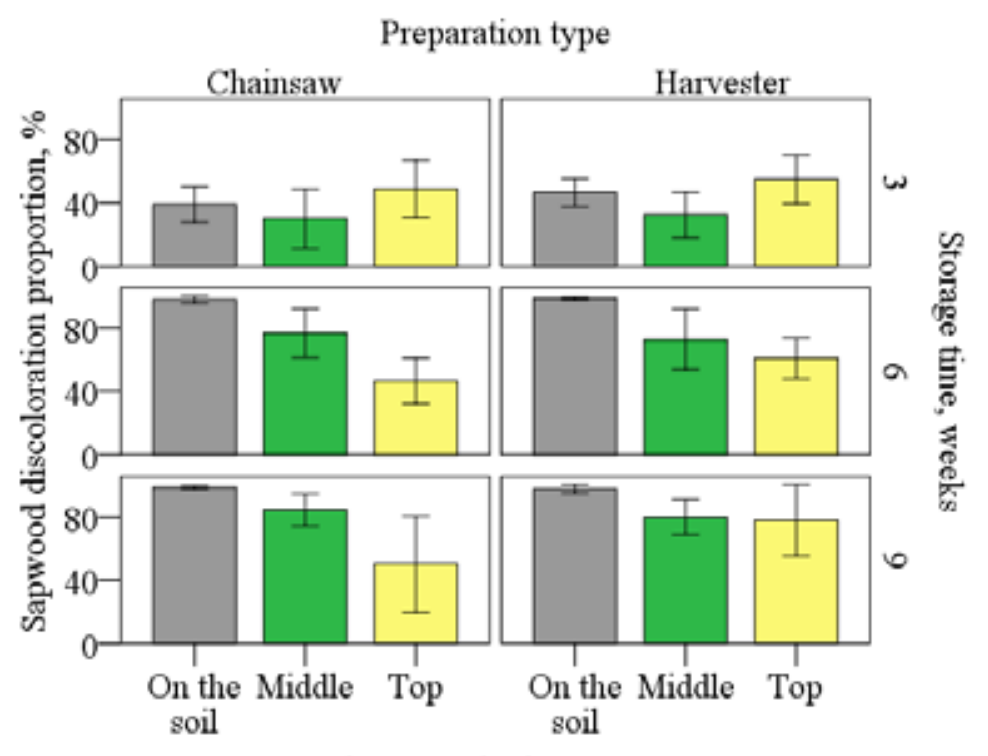

Placement in the storage

Figure 3. The development of birch sapwood discoloration depending on the preparation type, storage length and placement in the storage (with \pm 2 standard errors). 

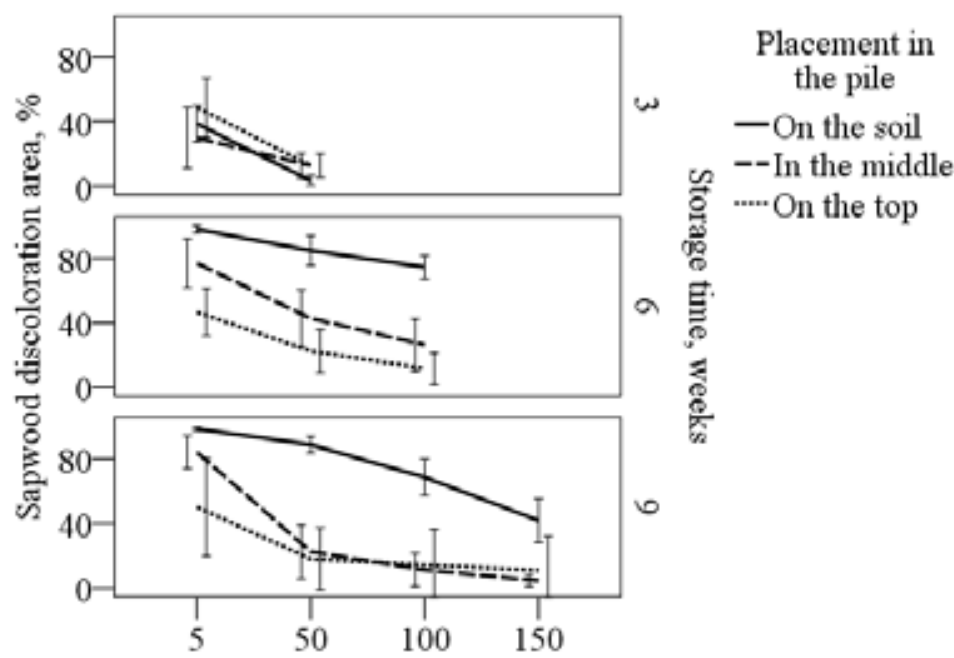

Distance from the end plane, $\mathrm{mm}$

Figure 4. The development of birch sapwood discoloration depending on the preparation type, storage length and distance from the end plane - prepared with chainsaw (with \pm 2 standard errors).

occupies around $32 \%$ of the cross-sectional sapwood area. After 6 weeks, the discoloration proportion more than doubles $(73 \%)$ and after 9 weeks it is $80 \%$. In this case also the most intensive development of sapwood discoloration for birch occurs for the assortments stored in the bottom section of the storage. Birch logs that are in direct contact with soil show $46 \%$ after 3 weeks and up to $98 \%$ of sapwood discoloration proportion after 6 and 9 weeks of storage.

By analysing the distance from the end plane, it can be observed that round assortments which are prepared with the harvester have a higher proportion of sapwood discoloration. It can be explained by the fact that the discoloration process in similar conditions for these birch round assortments begins faster compared to the assortments prepared with a chainsaw.

When the birch round assortments are prepared with a chainsaw, it can be observed that after 3 weeks of placement in the storage, it does not significantly influence sapwood discoloration development depending on the distance from the end plane - at $5 \mathrm{~mm}$ distance discoloration proportion ranges from $30 \%$ to $49 \%$, at $50 \mathrm{~mm}$ it is from $3 \%$ to $13 \%$.

After 6 and 9 weeks of placement in the storage, a significant influence can be observed on the sapwood discoloration development depending on the distance from the end plane. A higher proportion of sapwood discoloration is for assortments that are placed on the soil (see Fig. 4).

When the birch round assortments are prepared with the harvester, it can be observed that after 3 weeks of placement in the storage, sapwood discoloration development has not been significantly influenced, depending on the distance from the end plane - at $5 \mathrm{~mm}$ distance discoloration proportion ranges from $32 \%$ to $55 \%$, at $50 \mathrm{~mm}$ distance from $8 \%$ to $21 \%$.
After 6 and 9 weeks of placement in the storage, sapwood discoloration development is significantly influenced, depending on the distance from the end plane. A higher sapwood discoloration proportion is for assortments that are placed on the soil. After 6 and 9 weeks of storage, there are no significant differences depending on the distance from the end plane for assortments, which are placed in the middle or on the top of the storage (see Fig. 5).

In order to more fully describe the changes in sapwood discoloration proportions in the springsummer period, the multiple linear regression analysis is used to analyse the wider effect of the influencing factors. The general task of regression analysis is to study the relationship between the dependent variable (sapwood discoloration proportion) and predictors (preparation type, side surface damage, placement in the storage, storage length, the diameter of round assortments, the distance from the end plane, the daily average temperature, amount of precipitation and relative air humidity) and to evaluate the correlation of predictors.

When regression analysis is applied, the birch round assortment placement in the storage is recoded in the digital form ( 1 - on the soil, 2 - in the middle, 3 - on the top). The type of preparation also is recoded in the digital form ( 1 - chainsaw, 2 - harvester $)$.

Factors that significantly affect the sapwood discoloration development are: the preparation type, placement in the pile, distance from the end plane, the average daily temperature and relative air humidity (see Table 2).

Determination coefficient $\mathrm{R}^{2}$ for linear regression is 0.450 , indicating that $45 \%$ of the discoloration development cases of birch round assortments can be explained by these factors. 


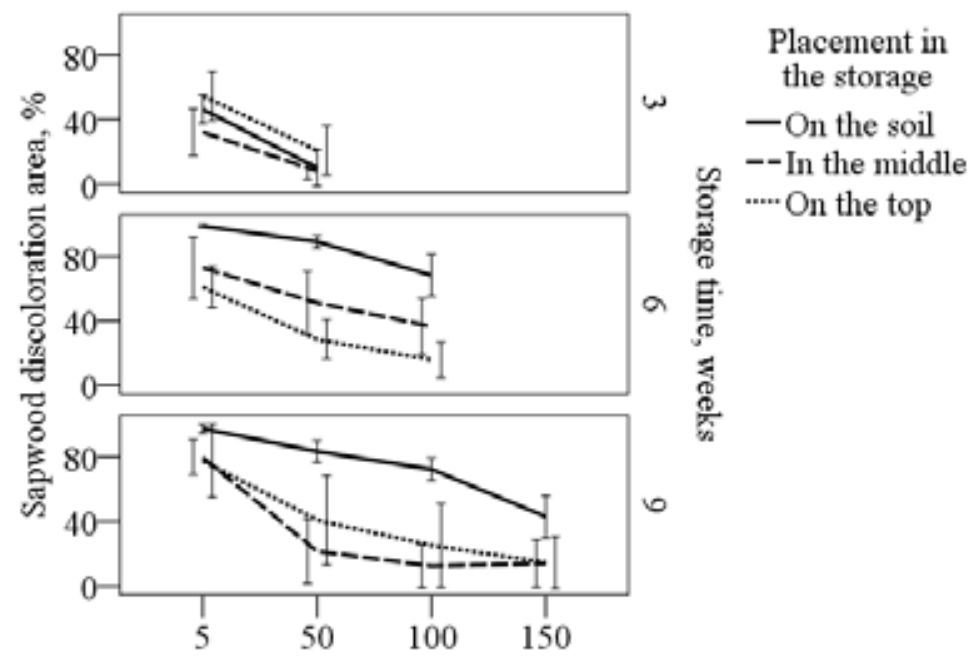

Distance from the end plane, $\mathrm{mm}$

Figure 5. The development of birch sapwood discoloration depending on the preparation type, storage length and distance from the end plane - prepared with harvester (with \pm 2 standard errors).

Table 2

The evaluation of significance of sapwood discoloration influencing factors

\begin{tabular}{|c|c|c|c|c|c|c|}
\hline Indicator & Coefficient & $\begin{array}{l}\text { Standard- } \\
\text { error }\end{array}$ & t stat. & $* p$ - value & $\begin{array}{l}\text { Correlation } \\
\text { coefficient (r) }\end{array}$ & $\begin{array}{l}\text { Determination } \\
\text { coefficient }\left(\mathrm{R}^{2}\right)\end{array}$ \\
\hline Constant & 133.599 & 36.986 & 3.612 & 0.000 & \multirow{6}{*}{0.671} & \multirow{6}{*}{0.450} \\
\hline Preparation type & 4.636 & 2.199 & 2.108 & 0.035 & & \\
\hline Placement in the storage & -17.252 & 1.390 & -12.408 & 0.000 & & \\
\hline $\begin{array}{l}\text { Distance from the end } \\
\text { plane, } \mathrm{mm}\end{array}$ & -0.417 & 0.025 & -16.379 & 0.000 & & \\
\hline $\begin{array}{c}\text { Average daily } \\
\text { temperature sum }\end{array}$ & 0.193 & 0.021 & 9.232 & 0.000 & & \\
\hline Relative air humidity, $\%$ & -1.884 & 0.568 & -3.315 & 0.001 & & \\
\hline
\end{tabular}

If $\mathrm{p}$ values are smaller than 0.05 , influence of the factor is significant.

In Sweden it was concluded that defects, such as cracks and rot, also contributed to the spread of discoloration on all studied tree species. For the birch top end assortments, on average, there is a little more stain than the for the butt end assortments. When comparing discoloration development, placing the roundwood top end on the sunny or shady side, there were no significant differences, only for birch logs prepared in winter and stored by the standard method on the sunny side, they had a deeper flamelike colouring than the ones stored in the shady side (Jonsson, 2013).

\section{Conclusions}

1. The main factors affecting the share of crosssectional area of browning in the round assortments during storage are: the preparation type, placement in the storage, the distance from the end plane, the daily average air temperature and relative humidity of the air.

2. With the average daily air temperature reaching $+6{ }^{\circ} \mathrm{C}$, the first signs of sapwood discoloration on birch roundwood prepared with a harvester would appear after 17 to 18 days of storage, and would spread to the whole stack of birch roundwood, prepared at the same time, after 68 to 69 days. However, with the average daily air temperature reaching $+18{ }^{\circ} \mathrm{C}$, the first signs of sapwood discoloration may appear already after 6 days of storage and spread to the whole stack of simultaneously prepared birch roundwood after 23 days.

3. With the average daily air temperature reaching + $6{ }^{\circ} \mathrm{C}$, the first signs of sapwood discoloration on birch roundwood prepared with a chainsaw would appear after 23 to 24 days of storage and would 
spread to the whole stack of birch roundwood, prepared at the same time, after 69 to 71 days. However, with the average daily air temperature reaching $+18{ }^{\circ} \mathrm{C}$, the first signs of browning may appear already after 8 days of storage and spread to the whole stack of simultaneously prepared birch roundwood after 24 days.

4. The most rapid development of browning is observed on the birch roundwood placed at the bottom of the stack; on the soil after 3 weeks of storage sapwood discoloration occupies $39-46 \%$ of roundwood end plane. After 6 to 9 weeks of storage, sapwood discoloration occupies $98 \%$ of round wood end plane.

\section{Acknowledgments}

The data for this research was collected in the framework of national research program Nr. 2014/ VPP2014-2017, sub-project 'Studies of timber processing, forest products logistics and planning'.

\section{References}

1. Corbo, M., Pape, R., \& Tegelmark, D. (2001). Storing timber of birch-a preliminary study (In Swedish with English summary). Research notes 13, Swedish University of Agricultural Sciences, Department of Forest Products and Markets.

2. Hallaksela, A-M., \& Niemisto, P. (1998). Stem discoloration of planted silver birch. Scandinavian Journal of Forest Research 13:169 - 176.

3. Jonsson, M. (2013). Wet storage for discolouration protection during roundwood storage of three Swedish hardwoods. European Journal of Wood and Wood Products, 71(2), pp. 219 - 225.

4. Liese, W., \& Peek, R.D. (1984). Experiences with wet storage of conifer logs. Dansk Skovforeningstidsskrift, LXIX(1): $73-91$.

5. Nylinder, M., Pape, R., \& Fryk, H. (2001). Björktimmer - förädling, egenskaper och skador. (Birch timber - manufacturing, properties and damage), Swedish University of Agricultural Sciences, ISBN 91-5766024-7, Uppsala (in Swedish).

6. Nylinder, M., Woxblom, L., \& Fryk, H. (2007). Ädellöv-virke och förädling. (Valuable hardwoods-wood and processing), Swedish University of Agricultural Sciences, Uppsala (in Swedish).

7. Peek, R.D., \& Liese, W. (1974). Erfahrungen mit der Beregnung von Sturmholz. Forst- und Holzwirt(Experience with the sprinkling of windblown trees. Woodworking host) 29:261-263. (in German).

8. Shigo, A.L. (1965). Organism interactions in decay and discoloration in beech, birch, and maple. Research Paper NE-47, U.S. Forest Service.

9. Stahl, E.G., Karlmats, U., \& Olsson Tegelmark, D. (2005). Colour and discolouring of birch sawn timbervariation and effects of harvesting date, saw timber storage and drying of sawn goods (In Swedish with English summary). Report 27, Dalarna University, Department of Forestry and Wood Technology.

10. Uzunovic, A., Byrne, T., Gignac, M., \& Dian-Qing, Y. (2008). Wood Discolourations and their Prevention [online]. FPInnovations, Canada. Retrieved April 12, 2016, from: https://fpinnovations.ca/media/ publications/Documents/wood-discoloration.pdf. 